\title{
Desarrollo y pobreza en México, Argentina, Brasil y Chile
}

\author{
Ernesto H. Turner Barragán \\ Universidad Autónoma de México, Sede Azcapotzalco, Ciudad de México, México. \\ Email: etb@hotmail.com
}

Resumen: Se sostiene que la pobreza en América Latina no es un hecho contemporáneo, sino algo que afectaba desde la colonia a gran parte de la población. Se retoman algunos aspectos del caso mexicano para explicar que son condiciones históricas las que dan pie a la brecha del crecimiento económico entre América Latina y Estados Unidos, así como la desigualdad de los ingresos. Se ejemplifica esto con los casos de México, Argentina, Brasil y Chile, respecto de EUA, Japón y Alemania, presentando la evolución del PIB per capita y la distribución del ingreso de 1980 a 2010. Se distingue la pobreza extrema de la moderada, siendo en esta última que el individuo no tiene acceso a los bienes comúnmente obtenidos por la mayoría de los individuos de su comunidad, aunque puede satisfacer sus necesidades básicas. Como parte de la pobreza moderada desglosa la pobreza de capacidades y de patrimonio. Finalmente con base en el planteamiento de la pobreza se analiza la pobreza en México, Argentina, Brasil y Chile en las últimas décadas.

Palabras clave: distribución del ingreso, pobreza moderada, pobreza extrema.

\section{Development and poverty in Mexico, Argentina, Brazil and Chile}

\begin{abstract}
It is argued that poverty in Latin America is not a contemporary phenomenon, but something affecting a wide sector of the population since the colonial period. It incorporates some aspects of the Mexican case to explain that are historical conditions which give rise to the economic growth gap between Latin America and the United States, as well as income inequality. This is exemplified in the cases of Mexico, Argentina, Brazil and Chile, en regards U.S., Japan and Germany, presenting the evolution of GDP per capita and income distribution from 1980 to 2010. It distinguishes extreme poverty from moderate poverty, being in the latter the one where the individual has no access to goods commonly obtained by most individuals in their community, but still can meet their basic needs. As part of moderate poverty it separates poverty from capabilities and assets. Finally, based on the approach to poverty, it analysis poverty in Mexico, Argentina, Brazil and Chile in the last decades.
\end{abstract}

Key words: income distribution, moderate poverty, extreme poverty.

\section{Desenvolvimento e pobreza no México, Argentina, Brasil e Chile}

Resumo: Argumenta-se que a pobreza na América Latina não é um 
fenômeno contemporâneo, mas algo que afeta desde a colônia a grande parte da população. Incorpora-se alguns aspectos do caso mexicano para explicar quais as condições históricas que dão origem a lacuna de crescimento econômico entre a América Latina e nos Estados Unidos, bem como a desigualdade de renda. Isto é exemplificado nos casos do México, Argentina, Brasil e Chile, para os EUA, Japão e Alemanha, apresentando a evolução do PIB per capita ea distribuição de renda de 1980-2010. Distingue-se a pobreza extrema da moderada, sendo neste último que o indivíduo não tem acesso aos bens comumente obtidos pela maioria dos indivíduos em sua comunidade, mas pode satisfazer suas necessidades básicas. Como parte da pobreza pobreza moderada distingue-se pobreza de recursos e pobreza de ativos. Finalmente, com base na abordagem da pobreza análiza-se esta no México, Argentina, Brasil e Chile nas últimas décadas.

Palavras-chave: distribuição de renda, pobreza moderada, pobreza extrema.

$* * *$

\section{Introducción}

La declaración sobre el Derecho al Desarrollo de las Naciones Unidas señala que el desarrollo "es un derecho humano inalienable en virtud del cual todo ser humano y todos los pueblos están facultados para participar en un desarrollo económico, social, cultural y político en el cual puedan realizarse plenamente todos los derechos humanos y libertades fundamentales. El acceso a los servicios básicos, como son educación, salud, alimentos, vivienda, empleo, y a la justa distribución de los ingresos aparece hoy como un derecho humano, en el cual se deberán apoyar los Gobiernos para erradicar la pobreza y dotar a los habitantes de sus países de una vida digna, que les permita desplegar plenamente sus capacidades y sustentar el desarrollo de la Nación.

En los años 40 se propagaron las teorías del desarrollo. La teoría supone que un aumento en el producto agregado o en el PIB per cápita, reduciría la pobreza e incrementaría el bienestar general de la población; toda producción genera rentas, por lo tanto, a mayores rentas mayores utilidades o mayor bienestar económico. Por ello, los economistas se convencieron de que era suficiente con apoyar el crecimiento para alcanzar el desarrollo. El debate se centró en torno a las formas en que se podía acelerar la producción de bienes y servicios. Sin embargo, hoy se ha reconocido que un aumento en la producción resulta insuficiente para reducir la pobreza y alcanzar el desarrollo.

El aumento de la producción se ha convertido, frecuentemente, en un proceso excluyente, cuando el incremento de la producción está acompañado por una expropiación de los medios de producción y la reducción de las capacidades de una parte creciente de la población, que se va empobreciendo y va a engrosar las filas de los pobres, como lo señaló K. Marx. Entonces, acumulación de capital y empobrecimiento y marginación son procesos que se dan en forma conjunta. Amartya Sen puso énfasis en que la 
eliminación de la pobreza no podría darse si a los pobres no se les dotaba de capacidades suficientes para incorporarse a la vida productiva y se les retribuía de manera justa, de acuerdo a su participación en la producción. Hoy en día, se reconoce la importancia del capital humano como uno de los elementos indispensables para alcanzar el desarrollo y la eliminación de la pobreza y se concibe el aumento del capital humano como la actividad dirigida a dotar de destrezas y capacidades productivas a toda la población. En suma, no se puede concebir el desarrollo sin considerar a las personas como el factor central, como el agente activo, innovador, creador y director de la actividad productiva, que es a la vez el fin mismo, su razón de ser, en tanto que el propósito de la actividad productiva es el mejoramiento del bienestar social, humano.

El artículo analiza la evolución de la producción y la pobreza en cuatro países de América Latina: Argentina, Brasil, Chile y México y se divide en 5 secciones. La primera sección está dirigida a mostrar el carácter histórico de la pobreza, y con ese fin se evocan algunos elementos históricos que limitaron el desarrollo de México, los que sirven para ilustrar que la pobreza durante la colonia era un fenómeno generalizado que afectaba a la mayor parte de los indígenas y que el retraso en el desarrollo económico de los países de América Latina, con respecto a los EUA, se generó, fundamentalmente, en el siglo XIX. En la segunda sección se analiza la evolución del PIB per cápita de los cuatro países estudiados, durante el siglo XX, con respecto a los EUA, con el fin de mostrar que la brecha que se generó entre sus productos per cápita y el de los EUA, se ha mantenido durante el siglo XX, y aún expandido a finales de siglo. En la tercera sección se analiza la evolución del PIB per cápita de los tres países más importantes de América Latina con respecto a los EUA, Japón y Alemania, con el fin de apreciar hacia donde tienden a converger, y se analiza también su distribución del Ingreso y evolución, de 1980 a 2010.

En la cuarta sección se presentan los enfoques teóricos que se han empleado para el estudio de la pobreza y su cuantificación, con el propósito de analizar en la quinta sección la evolución de la pobreza en México, Argentina, Brasil y Chile en las últimas décadas. Al final se presentan las conclusiones.

\section{Marco Histórico. La Gran Catástrofe Demográfica del siglo XVI}

Uno de los paradigmas de la historia de América Latina como de otras regiones en el Mundo que no logran erradicar la pobreza es su bajo desempeño económico comparado con el de países y regiones que han logrado desarrollarse. "Aunque en el período de la conquista y la colonización los países de América Latina eran pobres y atrasados en 
comparación con sus colonizadores, España y Portugal, la brecha era menor que hoy..., en el año 1500, el ingreso per cápita era probablemente el 50\% mayor que el promedio latinoamericano, en tanto que en la actualidad es alrededor del 300\% mayor”. (Robinson , J. en Fukuyama, F. 2006, p.197).

A la llegada de los españoles, las regiones económicamente más avanzadas no eran Canadá y Estados Unidos, sino México, Perú y Bolivia, países que estaban densamente poblados y que habían establecido civilizaciones centralizadas y complejas gracias al desarrollo de la agricultura y de las técnicas de irrigación. Los economistas suponen que la mayor integración global de las naciones es una fuerza poderosa a favor de la convergencia, de manera que la llegada de tecnologías europeas antes inexistentes, como la rueda, los barcos, la escritura, el dinero y la producción de acero, así como la súbita disponibilidad de cultivos nuevos (trigo) y de nuevas especies de ganado (equino, vacuno y porcino) debían haber permitido que los niveles de prosperidad se aproximaran entre Europa y América Latina. Pero no ocurrió así, y el arribo de los europeos con sus técnicas militares, sus sistemas laborales y sociales de explotación, su religión y cultura, desencadenaron una catástrofe demográfica sin precedentes en la historia humana, produjeron un severo estancamiento económico y social que se prolongó por más de tres siglos y una divergencia económica creciente.

Las primeras tres décadas de la colonización en México estuvieron acompañadas de una gran catástrofe demográfica, al desplomarse la población indígena de 16.8 millones en 1532 a 2.6 millones en 1568. A mediados del siglo XVII, la población total ya se elevaba a 3.8 millones.

\section{Cuadro 1 \\ Población indígena y española en la Nueva España: 1532-1810 (miles de habitantes)}

\begin{tabular}{|l|l|l|l|}
\hline Año & Indígenas & Españoles & Total \\
\hline 1532 & 16800 & 8 & 16808 \\
\hline 1568 & 2600 & 18 & 2618 \\
\hline 1650 & 3400 & 400 & 3800 \\
\hline 1795 & 3572 & 1628 & 5200 \\
\hline 1810 & 3676 & 2463 & 6139 \\
\hline & & & \\
\hline
\end{tabular}

Fuente: Garza, G., 2003, p.16.

Durante la segunda mitad del siglo XVII y casi todo el XVIII, la población creció muy lentamente, aumentando en tan sólo $10 \mathrm{mil}$ personas por año y en sólo1.4 millones en un siglo y medio, alcanzando los 5.2 millones en 1795. La limitación demográfica impidió que se poblaran las provincias del Norte, inmensas y amenazadas 
constantemente por los indios nómadas.

El aumento de la producción minera y la apropiación de la mayor parte del ingreso por parte de la Corona y de una pequeña élite interna durante la colonia española, se convirtió en un proceso excluyente, que privó a los indígenas no sólo de las posibilidades de alcanzar un bienestar material, económico y social mayor, sino también de todo derecho y de la posibilidad de aspirar a entablar un juicio, como asimismo de participación política, condenándolos a la esclavitud y a servir en la mita y en la encomienda. En consecuencia los indígenas fueron durante cuatro siglos desprovistos de sus derechos humanos, no pudiendo desarrollar sus capacidades en una época en que el desarrollo de la ciencia y la tecnología estuvo paralizado, por lo que la productividad del trabajo era muy baja y la concentración de la riqueza muy alta, por lo que la mayor parte de ellos vivieron en la pobreza. Entonces, la producción económica estuvo acompañada por el empobrecimiento y la marginación como procesos que se daban en forma conjunta, y la acumulación de un excedente no se convirtió ni en capital social, ni privado, sino que se exportó hacia la Corona.

En el siglo XVIII se desarrolló el sistema urbano colonial, que en un inicio se formó en torno a un eje principal, el cual requería únicamente del puerto de Veracruz para la importación y exportación de mercancías, y de la Ciudad de México para captar y centralizar su distribución. A él se agregaron la fundación de los reales de minas, los centros administrativos y militares y los centros de comercialización y abasto de las grandes haciendas. Mediante ese aparato administrativo se logró el control del interior del país y la afluencia de los excedentes económicos hacia la capital y de ahí hacia la metrópoli. Con la colonización de Texas termina la expansión de la Nueva España. La última etapa de expansión territorial de la Nueva España se llevo a cabo en el noreste. En 1823, el territorio del nuevo país independiente fue transformado en 25 provincias que fueron denominadas al año siguiente.

El sistema de ciudades novohispanas conformado en los tres siglos de la Colonia, giró en torno a los requerimientos de una economía esencialmente rural, minera, artesanal y comercial. En 1803, existían en México sólo 8 ciudades con más de 15 mil habitantes. La Ciudad de México contaba con 137 mil y era la principal urbe colonial; en ella se asentaba el poder político, militar y se monopolizaba las actividades comerciales, a ella y convergían las rutas principales (Garza, G, 1985). 


\section{Gráfica 1 \\ Sistema Urbano de México en 1803}

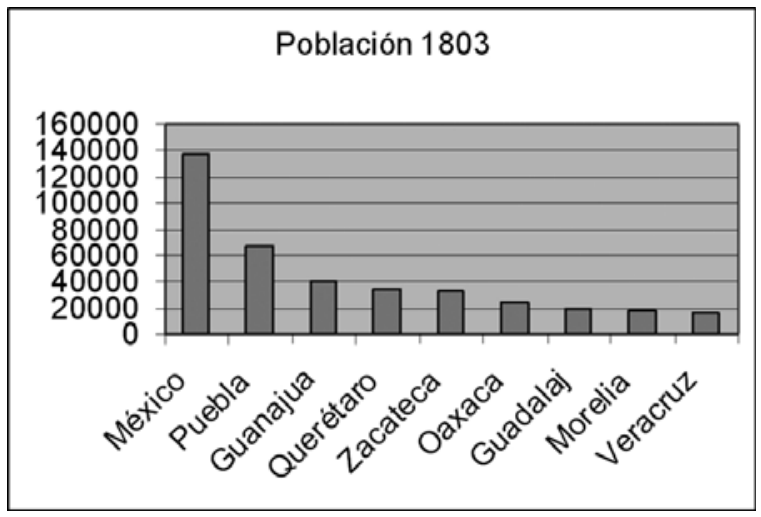

Fuente: Garza, G; 2003, 19.

La brecha en el ritmo de crecimiento económico entre América Latina y Estados Unidos -Producto Interno Bruto (PIB) per cápita- empieza a formarse en el siglo XVII, crece en el XVIII y se amplifica en el siglo XIX. El medio siglo que siguió a la independencia fue desastroso para México.

\section{Gráfica 2 \\ PIB per cápita de EUA, México, Brasil, Argentina y Chile: 1820-1921}

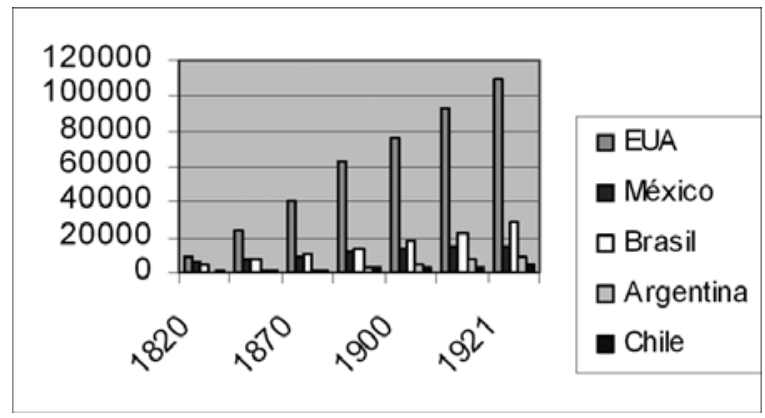

Fuente: Maddison, Angus, Monitoring the World Economy: 1820-1992, OCDE.

Así como la brecha del crecimiento económico entre América Latina y Estados Unidos ha sido grande a través del tiempo, también lo ha sido la desigualdad de ingresos de América Latina en comparación con Estados Unidos. La falta de variación en la distribución del ingreso se observa tam- 
bién comparando cada país con su propia historia. La combinación de ambas brechas implica que una gran parte de la población latinoamericana ha sufrido y sigue sufriendo el doble embate de un insuficiente crecimiento económico y de muy grandes limitaciones en su ingreso personal derivadas de una gran desigualdad en la distribución del ingreso y en la riqueza. A principios del siglo XX, el 75\% de las familias en Estados Unidos eran dueños de sus tierras en zonas rurales, mientras que la proporción de la familia dueñas de sus tierras en Argentina, en esos años, era inferior al 10\% y en México, inferior al 3\%

"En la época de la independencia de Estados Unidos, en 1776, las diferencias de prosperidad entre este país, México y Brasil eran mínimas... en el siglo XIX, la divergencia económica fue muy rápida. Hacia fines de 1820, la mayoría de los países latinoamericanos habían dejado atrás el colonialismo... Como naciones libres parecían estar en igual situación que las de América del Norte para aprovechar la gama de nuevas tecnologías provenientes de Gran Bretaña que asociamos a la Revolución Industrial... Los países de América del Norte no sólo adoptaron esas innovaciones sino que se convirtieron en innovadores dinámicos. América Latina, en cambio, se estancó. Hacia 1900, Estados Unidos era ya el país más próspero del Mundo, con un nivel de ingresos promedio del $400 \%$ superior al de América Latina... A partir de 1880, los países de América Latina comenzaron a crecer, pero... no lograron salvar esta brecha" (Robinson,J. en Fukuyama, F.; 2006, 200).

\section{Cuadro 2}

\section{PIB per cápita como \% del nivel de los EUA: 1800-1994}

\begin{tabular}{|l|c|c|c|c|c|c|}
\hline Pais & 1800 & 1850 & 1900 & 1913 & 1950 & 1994 \\
\hline Argentina & 102 & & 52 & 55 & 41 & 37 \\
\hline Brasil & 36 & 39 & 10 & 11 & 15 & 22 \\
\hline Chile & 46 & & 38 & 40 & 33 & 34 \\
\hline Colombia & & 34 & 18 & 18 & 19 & 24 \\
\hline México & 50 & 37 & 35 & 35 & 27 & 23 \\
\hline Perú & 41 & & 20 & 20 & 24 & 14 \\
\hline
\end{tabular}

Fuente: Robinson, J. en Fukuyama, F, 2006, 201.

El siglo XIX fue, para México, una época llena de conflictos armados internos y externos. Cabe mencionar: la guerra de Independencia que duró 11 años, de 1810 a 1821; la cual fue seguida por una serie de epidemias y, posteriormente por las guerras de independencia de Texas, en 1836, y la guerra con los EUA, de 1847-48, que concluyó con la pérdida de más de la mitad del territorio y su anexión a los EUA; estas guerras fueron seguidas por los conflictos entre conservadores y liberales que ocasionaron la guerra de Reforma de 1857, la intervención francesa y la instauración de la monarquía de Maximiliano de Habsburgo entre 1864 y 1865, la cual fue 
seguida, finalmente, por la dictadura de Porfirio Díaz que duró 34 años, de 1877 a 1910. A lo largo de esos conflictos, las burguesías y las clases medias liberales y republicanas pelearon por modificar el antiguo sistema político, económico y social, y por deponer al antiguo régimen monárquico e instaurar otro presidencial y democrático. A pesar de la consumación de la independencia en 1821 y de que se abolió la esclavitud, los indígenas y los mestizos continuaron siendo marginados económicamente al ser excluidos de la apropiación de la tierra, de la educación y la cultura; y al negárseles la participación dentro de las fuerzas militares y políticas que debatían la forma de organización económica y social del país. Durante la primera mitad del siglo fueron excluidos por los monarquistas que controlaron el Gobierno, pero durante la segunda mitad, también por los liberales, cuando a su vez controlaron el Gobierno. En la Constitución de 1857 fueron excluidos, al ser expropiadas las tierras de las comunidades indígenas junto con las tierras de las comunidades religiosas. Posteriormente, durante la dictadura de Díaz las tierras se cedieron a las compañías deslindadoras y a un selecto y reducido grupo de terratenientes que sometieron a los indígenas y a la mayor parte de la población a una relación de explotación feudal, laborando como peones en haciendas donde los dueños imponían su propia ley y fijaban los grados de explotación a su arbitrio.

A pesar de la violencia y la mortandad que acarrearon estos acontecimientos, la población aumentó de 6,1 millones a 15, 5 millones de habitantes, a una tasa de crecimiento anual de 0,9\%.Estos movimientos armados y políticos tuvieron un efecto devastador sobre la producción y las ciudades. No fue sino hasta la octava década del siglo XIX cuando las ciudades y la industria volvieron a crecer, con el impulso que les dio el sistema ferroviario y el eléctrico. En el último cuarto de siglo, la construcción de vías férreas avanzó aceleradamente hasta alcanzar 19280 km, en 1910. La introducción de la energía eléctrica inició, por su parte, hacia 1880, con la instalación de una planta hidroeléctrica, posteriormente, su construcción se multiplicó hasta alcanzar un total de 235 plantas, con una capacidad de 35 mil kilowatts, en 1899. Por su parte, a principios del siglo XX el sistema urbano quedó constituido por 18 ciudades, donde vivían casi un millón de habitantes, siendo el grado de urbanización de México muy incipiente, de 7.7\% (Garza, G. 2003).

"México se mantuvo como una nación esencialmente rural y sin una dinámica urbana significativa durante la época colonial y hasta las postrimerías del siglo XIX” (Garza, G; 2003; 22). Por ello, la pobreza estuvo asociada a la explotación laboral y a la marginación de la propiedad de la tierra a la que estuvieron sometidos los indígenas a lo largo de cuatro siglos. Los movimientos liberales y la Constitución de 1857 abolieron la propiedad de las comunidades indígenas y religiosas, pero en lugar de realizar una reforma agraria que distribuyera la tierra entre la población, durante la dictadura de Porfirio Díaz se concentraron las tierras quedando en manos de las compañías deslindadoras y de unos cuantos terratenientes, mientras que la mayor parte de la población fue sometida al peonaje, de manera que la industrialización, la urbanización y la modernización estu- 
vieron limitadas por el bajo ingreso per cápita de la población y el reducido tamaño del mercado interno. Las élites y los sectores que tenían un elevado poder de compra y se habían integrado a la modernidad, lo hacían por medio del mercado externo, exportando productos primarios que eran intercambiados por manufacturas.

\section{Evolución del PIB per cápita durante el siglo XX}

Se han adoptado en el Mundo diversas formas de medir el desarrollo económico y humano, el indicador más comúnmente utilizado ha sido el Producto Interno Bruto que cuantifica la capacidad de una economía para generar para elaborar bienes y servicios. Este indicador resulta sumamente sesgado, ya que no toma en cuenta el número de personas involucradas en la producción de la riqueza y no considera, tampoco, la forma en que la riqueza es distribuida entre la población. Por ello en las siguientes dos secciones describiremos en grandes líneas como evolucionó el PIB per cápita en Argentina, Brasil, Chile y México y como se ha venido dando la distribución del ingreso en las últimas décadas, con el fin de que estos elementos puedan servirnos para entender mejor como se ha producido el desarrollo y ha ido evolucionado la pobreza y el bienestar a lo largo del último cuarto de siglo.

Según John Catsworth, el PIB per cápita de América Latina, desde 1900 hasta nuestros días, ha sido casi invariablemente sólo algo más que la cuarta parte del de Estados Unidos. (Coatsworth, J y Taylor, A;1998). Sin embargo, el PIB per cápita de México, entre 1910 y 1940, sufre un considerable retraso debido a una crisis económica a principios de siglo XX, a la Revolución de 1910 a 1917 que le siguió y a la inestabilidad político-económica que sufrió el país hasta 1934. En esas 3 décadas y media, mientras que el PIB per cápita de Brasil aumentó en un 85\%; el de los EUA, en un $71 \%$, y el de Argentina, en un 50\%; el de México sólo creció en 34\%. Aunque la revolución y los Gobiernos postrevolucionarios abatieron la pobreza por la vía de una mejor distribución de la riqueza y una mayor equidad, entre 1910 y 1934,a través del reparto de tierras y el establecimiento de la Constitución de 1917, los niveles de pobreza en México siguieron siendo muy elevados debido al bajo crecimiento de la producción.

La pobreza se abatió en México, en forma significativa de 1934 a 1981, primero en el campo, gracias al amplio reparto de tierras que realizó Cárdenas, por medio del cual quedó en manos de campesinos ejidatarios la mitad de la tierra cultivada. Ello dinamizó la producción agrícola que creció a una tasa media del 5\%, entre 1934 y 1965. Sin embargo debido al fraccionamiento continuo de los predios campesinos, al rezago tecnológico y a la caída de los precios de los productos agrícolas, la tasa de crecimiento se abatió hasta caer a menos del 1\%, entre 1965 y 1975. Con ello, la pobreza rural avanzó expulsando migrantes hacia las ciudades. La pobreza se abatió, también en las ciudades, por el acelerado movimiento de industrialización y urbanización que se dio bajo el modelo de sustitución de impor- 
taciones que estuvo acompañado por un fuerte desarrollo del mercado interno y de las clases medias.

\section{Cuadro 3}

México: tasa de crecimiento media anual del PIB por sectores económicos: 1950-2005

\begin{tabular}{|l|c|c|c|c|c|c|}
\hline Pais & 1800 & 1850 & 1900 & 1913 & 1950 & 1994 \\
\hline Argentina & 102 & & 52 & 55 & 41 & 37 \\
\hline Brasil & 36 & 39 & 10 & 11 & 15 & 22 \\
\hline Chile & 46 & & 38 & 40 & 33 & 34 \\
\hline Colombia & & 34 & 18 & 18 & 19 & 24 \\
\hline México & 50 & 37 & 35 & 35 & 27 & 23 \\
\hline Perú & 41 & & 20 & 20 & 24 & 14 \\
\hline
\end{tabular}

Fuente: Lechuga, J; 2005;

“Concluida la depresión económica del comercio internacional a mediados de los años treinta y transcurrido el período de la Segunda Guerra Mundial, la mayoría de los países latinoamericanos pudo resurgir, al principio con lentitud, a una etapa de crecimiento sostenido. Durante los años cincuenta y sesenta, y aún parte de los setenta, o sea por casi 30 años, la región latinoamericana experimentó constante expansión económica, expresada en aspectos importantes de modernización e industrialización, con incorporación de nuevas tecnologías, mejoramiento de la agricultura comercial, y ampliación extensa de la infraestructura y de las comunicaciones internas...El desarrollo se concibió como un proceso que incluía el cambio social y el mejoramiento del bienestar humano. Se alcanzaron metas cada vez más elevadas de avance social, sobre todo en materia de educación, vivienda, salud y consolidación urbana (Urquidi, V; 2005; 25).

\section{Gráfica 3 \\ PIB per cápita de EUA, México, Brasil, Argentina y Chile: 1921-1994}

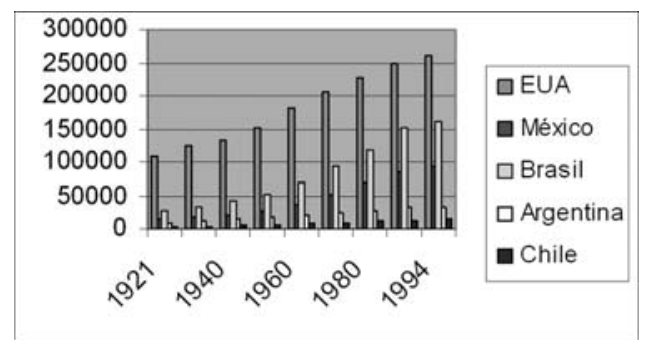

Fuente: Maddison, Angus, Monitoring the World Economy: 1820-1992, OCDE. 


\section{Evolución del PIB per cápita y la Distribución del Ingreso: 1980-2010}

\section{Evolución del PIB per cápita en países seleccionados: 1970-2009}

Como puede observarse en la Gráfica 4, los EUA, Japón y Alemania han mantenido trayectorias similares de incremento del PIB per cápita, de 1970 al 2010. Japón redujo su brecha con respecto a los EUA, entre 1970 y 1987, incluso llegó a superar a los EUA entre 1988 y 1999; Alemania alcanzó a los EUA entre 1988 y 1997 y luego amplio su brecha entre 1997 y 2003, pero todos ellos han mantenido trayectorias crecientes en el largo plazo. En el caso de los países de América Latina, en cambio, Argentina mantiene su brecha en los años setenta, representando su ingreso per cápita la quinta parte del de los EUA, y luego la amplia durante la década de los ochenta, entre 1989 y 1991, su ingreso per cápita sólo fue la décima parte del de los EUA, y aunque se recuperó temporalmente en la década de los noventa, su ingreso per cápita cae nuevamente entre 2002 y 2006.

\section{Gráfica 4 \\ PIB per cápita países seleccionados}

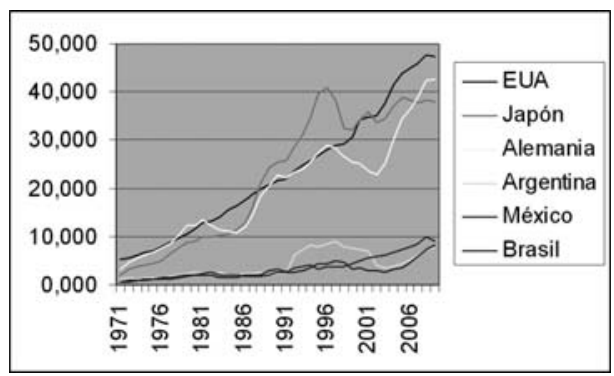

Brasil y México cerraron la brecha en la década de los setenta, por lo que su ingreso per cápita llegó a representar poco menos de la quinta parte del de los EUA en 1980. En los años 80 su producto per cápita cae, como consecuencia de las crisis económicas provocadas por el cambio de modelo, el endeudamiento externo y por las políticas de estabilización que se aplicaron, por lo que se volvió a ampliar la brecha y su PIB per cápita sólo llegó a representar un décimo del PIB per cápita de los EUA, a finales de los ochenta. En los años 90, nuevamente se va a ir cerrando la brecha que los separa de los niveles de ingreso alcanzados por los EUA y los países desarrollados, pero esa tendencia se vuelve a revertir en los primeros años del nuevo siglo. Actualmente, en 2009, Argentina, Brasil, Chile y México tienden a converger hacia un mismo valor, representando su producto per cápita 1/6 del PIB per cápita de los EUA. 


\section{Gráfica 5 \\ PIB per cápita de países seleccionados: 2000-2007}

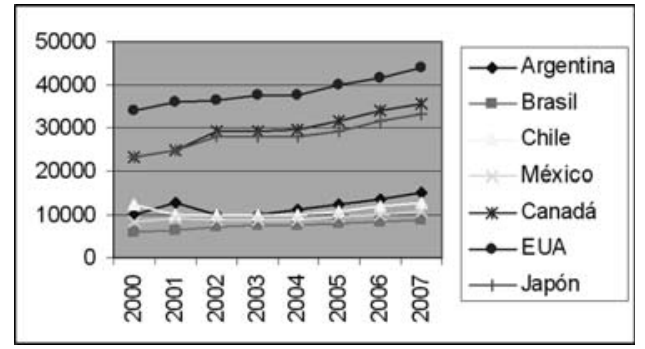

Como puede observarse, las diferencias entre los ingresos per capita de los países de América Latina seleccionados: Argentina, Chile, México y Brasil, tienden a cerrarse y a converger hacia un valor medio de 10 mil dólares entre el 2002 y el 2004 y luego a volverse a abrir para el 2007, su producto per cápita aumenta poco y erráticamente, mientras que en el caso de los EUA, Canadá y Japón se observa un aumento sostenido y un aumento de más de 10 mil dólares en los tres casos.

\section{Distribución del Ingreso de México, Argentina, Brasil y Chile: 1980-2002}

En la gráfica 6, se presenta la distribución del ingreso en México y se observa cómo el $60 \%$ de la población de menor ingreso que recibía el 13\% del ingreso en 1963, mejoró su ingreso hasta alcanzar el 23\% en 1984. A partir de ese año y hasta el 2000 su ingreso se ha estabilizado alrededor del $20 \%$.

El 10\% de la población más rico que recibía la mitad del ingreso, en 1963, redujo su participación hasta un 38\%, en 1984 y posteriormente, volvió a incrementarla hasta alcanzar entre el $45 \%$ y el $50 \%$ del ingreso. Las clases medias, formadas por los deciles VI al X, también incrementaron su participación de un 34\% en 1963 a un 39\% en 1984, para reducir su participación a 1/3 del ingreso hasta el 2000. 


\section{Gráfica 6 \\ Distribución del Ingreso en México: 1963-2000}

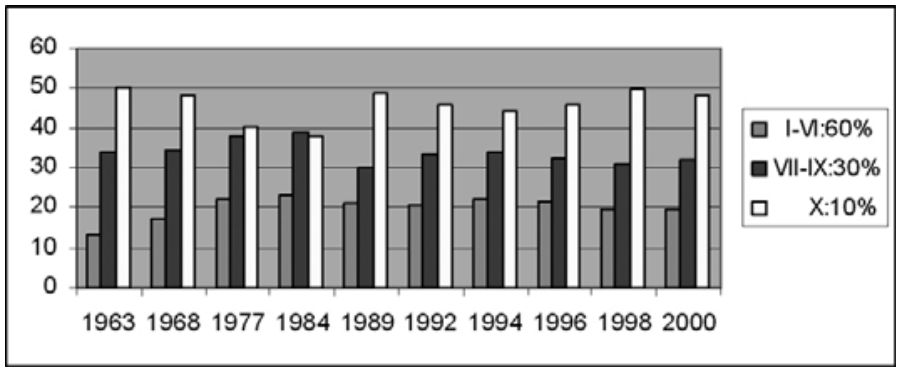

El 10\% de la población más rico que recibía la mitad del ingreso, en 1963, redujo su participación hasta un 38\%, en 1984 y posteriormente, volvió a incrementarla hasta alcanzar entre el $45 \%$ y el $50 \%$ del ingreso. Las clases medias, formadas por los deciles VI al X, también incrementaron su participación de un 34\% en 1963 a un 39\% en 1984, para reducir su participación a 1/3 del ingreso hasta el 2000. 1980 a 2002.

La gráfica 7 nos muestra la distribución del ingreso en Argentina de

El 60\% de la población de menor ingreso redujo su participación del 33\%, en 1980, al 27\%, en el 2002, al igual que las clases medias, formadas por los deciles VI al IX, que redujeron su participación del 36\%, en 1980, al 32\%, en 2002. Por su parte el decil más rico incrementó su participación del 31\%, en 1980, al 41\%, en 2002.

\section{Gráfica 7}

\section{Distribución del Ingreso en Argentina: 1980-2002}

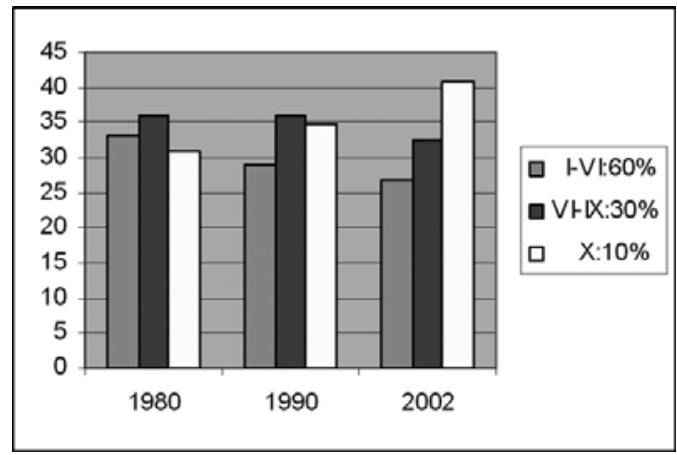

Fuente: CEPAL, Panorama Social, 2006. 
El 60\% de la población de menor ingreso redujo su participación del 33\%, en 1980, al 27\%, en el 2002, al igual que las clases medias, formadas por los deciles VI al IX, que redujeron su participación del 36\%, en 1980, al 32\%, en 2002. Por su parte el decil más rico incrementó su participación del 31\%, en 1980, al 41\%, en 2002.

La gráfica 8 nos muestra la distribución del ingreso en Brasil entre 1980 y 2002, se observa que el, 60\% de la población de menor ingreso mantuvo la misma proporción del ingreso de tan sólo 21\% entre 1980 y 2002, las clases medias formadas por los deciles VI al IX, sufrieron una pérdida al reducirse la proporción del ingreso que reciben del $37 \%$ al $33 \%$, mientras que el $10 \%$ de los más ricos, aumentó su participación del $42 \%$ al $46 \%$.

\section{Gráfica 8 \\ Distribución del Ingreso en Brasil: 1980-2002}

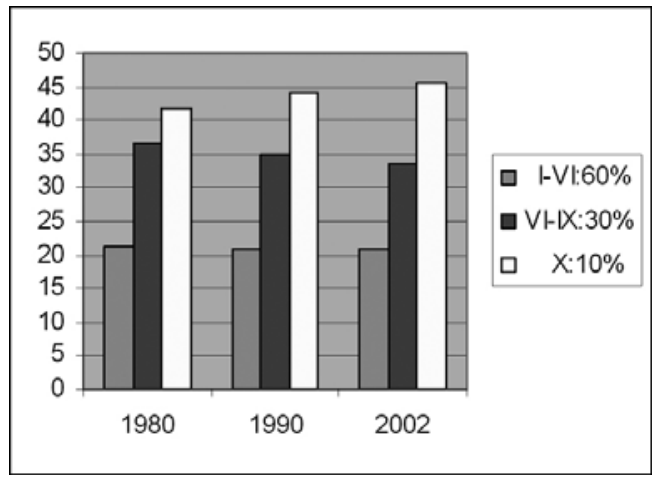

Fuente: CEPAL, Panorama Social, 2006.

La gráfica 9 nos muestra la distribución del ingreso de Chile entre 1980 y 2002, como se observa no hubo cambios importantes en la distribución del ingreso, de manera que el 60\% de la población con menor ingreso ha estado recibiendo un $26 \%$ del ingreso, las clases medias, deciles VI al IX, han estado recibiendo un 35\% del ingreso, participando el $10 \%$ de los más ricos con el 39\% del ingreso. 


\section{Gráfica 9 \\ Distribución del Ingreso en Chile: 1980-2002}

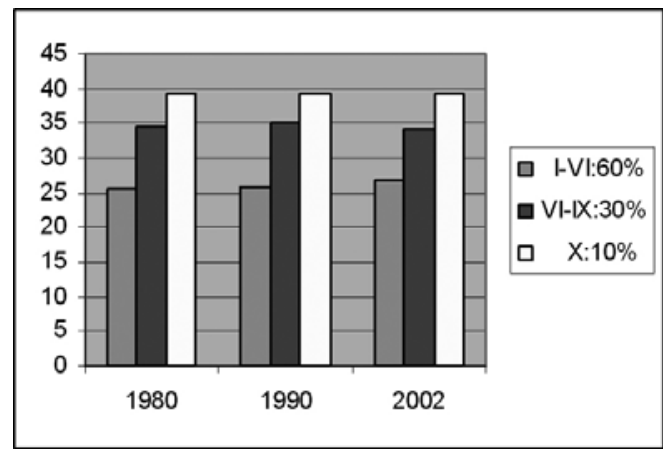

Fuente: CEPAL, Panorama Social, 2006.

El grave estancamiento de la producción y el elevado deterioro en la distribución del ingreso han tenido como resultado que se sepulte la idea de convergencia en el ámbito internacional al ampliarse la brecha entre los países desarrollados y los subdesarrollados.

\section{Marco Conceptual: Definición de la Pobreza y sus Causas}

\section{Definición de pobreza}

La medición de la pobreza tiene una connotación de carácter económico que está relacionada con la magnitud del ingreso y la posibilidad de adquisición de una canasta de bienes que permitan la satisfacción de necesidades consideradas básicas, su combate y desarrollo tienen una connotación sociológica, que se refieren a la exclusión que sufren los pobres de las clases y grupos sociales por su condición y medio ambiente, evocan la dificultades que enfrentan los pobres para adquirir ciertas capacidades como la educación, la civilidad y la cultura que son necesarias para participar en los mercados de trabajo y afectan su conducta. El análisis interdisciplinario del fenómeno de la pobreza y los avances conceptuales han permitido una mejor comprensión de los problemas de la pobreza y de la informalidad creciente que se presenta en México y en América Latina y con ello, de las formas en que se puede combatir la pobreza e ir reduciendo.

La pobreza es una situación de carencia que impide que las personas sean capaces de alcanzar niveles de bienestar considerados mínimos según criterios específicos, el más estricto, es el alimentario y designa a las personas que se encuentran en pobreza extrema, ellas son aquéllas que no tienen los medios necesarios para alimentarse y no son, por tanto, capaces, siquiera, de asegurar su subsistencia. Desde una perspectiva reducida, en- 
focada exclusivamente al estudio y medición de la pobreza, podemos adoptar como concepto de pobreza el que alude a la insatisfacción de un conjunto de necesidades consideradas esenciales que reflejan la forma y el estilo de vida de esa sociedad. Ello nos permite medir la pobreza en términos del ingreso percibido y establecer una línea o umbral de pobreza, que puede compararse con el valor de la canasta de satisfactores básicos mínimos a los que debiera poder acceder el individuo para no ser considerado pobre. Surgen, así, dos formas de medición, el método de la línea de pobreza (LP), enfoque indirecto que establece un ingreso monetario mínimo como criterio, y el método de las necesidades básicas insatisfechas (NBI), enfoque directo que designa una canasta de bienes que satisfacen el nivel considerado mínimo de bienestar. Los dos métodos son complementarios.

La definición de pobreza, recientemente, ha sido desarrollada ampliamente, al quedar enmarcada dentro de la teoría del bienestar general y del desarrollo humano. De esta manera, la estimación del bienestar individual que alcanza un individuo en una sociedad exige el análisis previo de la situación socioeconómica general de cada área o región y de los patrones culturales que expresan el estilo de vida dominante en ella, ya que la satisfacción de un conjunto de necesidades determina la eventual exclusión o forma de participación de una persona en la sociedad. Amartya Sen, desarrolló el concepto de pobreza de capacidades, al definir la pobreza en términos de las limitaciones, que encuentra una persona para realizar sus aspiraciones, incluidas la libertad y las posibilidades de decisión que tiene un individuo para alcanzar sus metas. En este contexto, la pobreza queda definida, tanto, en términos de las capacidades humanas que posee un individuo, como en términos de las posibilidades y habilidades que encuentra para desarrollarlas, tanto, en términos económicos, como políticos. Acorde con esta definición, el Programa de las Naciones Unidas para el Desarrollo (PNUD), considera al desarrollo humano como un proceso de ampliación de las opciones de la gente, tanto de su nivel de bienestar, como de la libertad y de la posibilidad de realización plena de un individuo. La pobreza significa que se niegan a un individuo, en un país, las oportunidades y las opciones más fundamentales del desarrollo humano: vivir una vida larga, sana y creativa; disfrutar: de un nivel de vida satisfactorio, de libertad, de la dignidad y el respeto por sí mismo y por los demás. El individuo en situación de pobreza extrema es el que vive una vida que no valora, que logra subsistir apenas, el que vive marginado y repudiado, por lo que ve a la sociedad con rencor; por lo que es propenso a delinquir y a caer en el vicio, tiende a deprimirse y a creer que no superará su condición de exclusión, por lo que se debate en el círculo vicioso de la pobreza. Esta definición muestra porque un apoyo meramente alimentario puede no ser suficiente para superar la condición de pobreza. La pobreza es, entonces, una condición inaceptable de vida, una restricción dramática de las libertades y capacidades de los individuos. No se trata simplemente de un bajo nivel de desarrollo humano, caracterizado por una alimentación insuficiente y un acceso limitado a la salud y a la educación, sino de un nivel inaceptable de desarrollo humano. La distinción entre tipos de pobreza es, entonces, de gran trascendencia analítica por las derivaciones que surgen para el diseño 
y la ejecución de políticas públicas, se podría decir que la pobreza extrema es una condición absoluta, mientras que la pobreza moderada es una condición relativa.

\section{Pobreza extrema}

Cuantitativamente, la pobreza extrema, línea 1 , se define a partir de un nivel de ingreso cuyo monto no permite consumir ni siquiera la cantidad mínima de alimentos que permiten un despliegue adecuado de las capacidades personales, dicho nivel se ha relacionado generalmente con la alimentación, por lo que, si se quiere medir la pobreza alimentaria debe hacerse mediante la comparación directa del gasto alimentario contra el costo de la canasta normativa alimentaria. El Banco Mundial para facilitar la comparación entre países, ha establecido que 1 dólar per cápita de ingreso diario es un criterio adecuado para definir la pobreza extrema. Se considera que la pobreza extrema constituye una situación de marginación total, ya que no se tienen las capacidades, ni existen posibilidades, ni oportunidades para remontarla. La condición de marginalidad es tan grave que quienes se encuentran en pobreza extrema, no están en posibilidades de acceder a ninguna oportunidad de crecimiento y desarrollo. La evidencia histórico empírica demuestra que la pobreza extrema se reproduce, generacionalmente, se trata de una situación que el mercado no puede corregir, por lo que el Estado debe asumir la responsabilidad de erradicarla.

Las políticas gubernamentales para erradicar la pobreza extrema han resultado ineficaces porque han padecido de una doble discriminación. Por una parte, debido a que el monto de recursos destinados a infraestructura, inversión social y apoyo alimentario en las zonas marginadas ha sido muy bajo, insuficiente para erradicarla, por otra, porque los recursos canalizados a dichas áreas, han sido desviados o no han logrado llegar hasta las personas más pobres, y han beneficiado a los líderes y productores más acomodados, de ahí la importancia de su adecuada focalización, del control estricto de su asignación y de la transparencia de los programas públicos.

\section{Pobreza moderada: pobreza de capacidades y pobreza patrimonial}

En términos cuantitativos, la pobreza moderada está definida a partir de un patrón normativo de consumo, cuyo monto de ingresos permitiría a las personas o familias vivir cubriendo satisfactoriamente además de la alimentaria, varias de sus necesidades que se consideren básicas, dado el nivel de desarrollo del país. Las personas u hogares moderadamente pobres, aunque viven con un nivel de bienestar inferior y padecen cierto grado de marginación, son capaces de desempeñarse en forma aceptable y aprovechar las oportunidades que el mercado y el desarrollo les ofrece, por lo que pueden capacitarse a través de los programas de educación pública y competir en el mercado de trabajo, logrando, con el tiempo, tener cierta movilidad social y acceder a niveles de bienestar más altos, de manera que pueden superar su condición reduciendo su tiempo de esparcimiento y de- 
dicándolo al trabajo y superación personal. En la pobreza moderada, las condiciones sociales y económicas circundantes brindan las oportunidades para superar esa condición, mediante el esfuerzo individual realizado en un contexto de crecimiento económico y desarrollo social sostenidos. Se considera que a los moderadamente pobres se les puede ayudar mejor con políticas que amplíen las oportunidades a que tienen acceso, es decir, con políticas de mercado. A diferencia de la pobreza extrema, una persona que padece de pobreza moderada no tiene acceso a los bienes comúnmente obtenidos por la mayoría de los individuos de su comunidad, pero, si puede satisfacer sus necesidades básicas.

La Secretaría de Desarrollo Social, determina dos líneas para la pobreza moderada, distinguiendo entre pobreza de capacidades y pobreza de patrimonio:

a) La pobreza de capacidades, línea 2, incluye a los hogares cuyo ingreso es insuficiente para cubrir los gastos de educación, salud y transporte mínimos necesarios para incorporarse al mercado de trabajo.

b) La pobreza de patrimonio, línea 3, incluye a los hogares, cuyo ingreso es insuficiente para cubrir sus necesidades de educación, vestido, calzado, vivienda, provisión de enseres domésticos y artefactos para el hogar, por lo que viven al día y son incapaces de desarrollar un patrimonio familiar y de acumular capital físico y humano que incremente progresivamente su condición social y bienestar.

c) La pobreza de patrimonio incluye a los hogares, cuyo ingreso es insuficiente para cubrir sus necesidades de educación, vestido, calzado, vivienda, provisión de enseres domésticos y artefactos para el hogar, por lo que viven al día y son incapaces de desarrollar un patrimonio familiar y de acumular capital físico y humano que incremente progresivamente su condición social y bienestar.

\section{Evolución de la Pobreza en México, Argentina, Brasil y Chile: 1980-2005}

Existen dos explicaciones principales de la pobreza extrema relacionadas con la dificultad que tienen las personas y algunas comunidades para incorporarse a la vida productiva del país, a la modernidad. Ellas explican 1) la pobreza rural, que existe en comunidades indígenas y menores a 5 mil habitantes y 2) la pobreza urbana asociada al desempleo y al empleo informal. Estas nociones sirven para localizar espacialmente las zonas marginadas de los países, en donde la mayor parte de las personas que habitan en ellas padecen de pobreza y de pobreza extrema. De acuerdo a datos publicados por el INEGI el porcentaje de la población pobre que se encuentra en el medio rural en México, ha ido disminuyendo en términos 
relativos. El porcentaje de la población pobre que vive en el campo se redujo de un poco más de la mitad, en 1950, a un $25 \%$ en el 2000 , ello se debe al avance del proceso de urbanización y a los programas de lucha contra la pobreza. De acuerdo con los datos que nos proporciona el Panorama Social de la CEPAL, el 60\% de la población rural en América Latina, vive en la pobreza y en la pobreza extrema, la tercera parte de la población.

En 1980,136 millones de personas, el 40\% de la población de América Latina, vivía en la pobreza, 73 millones de ellos habitaban en el campo y el resto, 63 millones, en las ciudades; 62 millones de los pobres eran indigentes y 40 millones de ellos vivían en el campo, como se observa en el Cuadro 4. A lo largo de los años ochenta la pobreza se incrementó tanto en números absolutos, a 200 millones de personas, como relativos, para representar el $48 \%$ de la población total.

\section{Cuadro 4}

Pobreza e Indigencia en América Latina: 1980-2005 millones de habitantes

\begin{tabular}{|c|c|c|c|c|c|c|}
\hline & $\begin{array}{c}\text { Pobreza } \\
\text { Urbana }\end{array}$ & $\begin{array}{c}\text { Pobreza } \\
\text { Rural }\end{array}$ & $\begin{array}{c}\text { Pobreza } \\
\text { Total }\end{array}$ & $\begin{array}{c}\text { Indigencia } \\
\text { Urbana }\end{array}$ & $\begin{array}{c}\text { Indigencia } \\
\text { Rural }\end{array}$ & $\begin{array}{c}\text { Indigencia } \\
\text { Total }\end{array}$ \\
\hline 1980 & 62,9 & 73 & 135,9 & 22,5 & 39,9 & 62,4 \\
\hline 1990 & 121,7 & 78,5 & 200,2 & 45 & 48,4 & 93,4 \\
\hline 1997 & 125,7 & 78,2 & 203,8 & 42,2 & 46,6 & 88,8 \\
\hline 1999 & 134,2 & 77,2 & 211,4 & 43 & 46,4 & 89,4 \\
\hline 2002 & 146,7 & 74,8 & 221,4 & 51,6 & 45,8 & 97,4 \\
\hline 2004 & 146,5 & 71 & 217,4 & 47,6 & 40 & 87,6 \\
\hline 2005 & 137,9 & 71,1 & 209 & 41,8 & 39,3 & 81,1 \\
\hline
\end{tabular}

Fuente: CEPAL; Panorama Social de América Latina; 2006; p.59.

Entre 1990 y 2002, el número de pobres se incrementó en forma absoluta de 200 a 221 millones y descendió a 209 millones entre 2002 y 2005, en términos relativos la pobreza se redujo del $48 \%$ de la población al $40 \%$, entre 1990 y 2005; 81 millones de esos 209 millones de pobres, eran indigentes, la mitad de ellos, habitaban en las ciudades y la otra mitad en el campo.

\section{Evolución de la Pobreza en Argentina en la década de los Noventa.}

La pobreza en Argentina, en los años 50, era poco significativa, afectaba a menos del $10 \%$ de los hogares y la indigencia no era considerable, sólo afectaba unas cuantas poblaciones rurales. El lento crecimiento del PIB per cápita, en los 50, de tan sólo 2.3\%, y moderado, en los sesenta, de $3.2 \%$, y una distribución del ingreso que se iba concentrando, llevó a que el proceso de urbanización se acompañara por el surgimiento de la pobreza en algunas ciudades, de manera que la pobreza urbana afectó al 3.5\% de los hogares, en 1970. 


\section{Gráfica 10 \\ Evolución de la Pobreza en Argentina: 1990-2005}

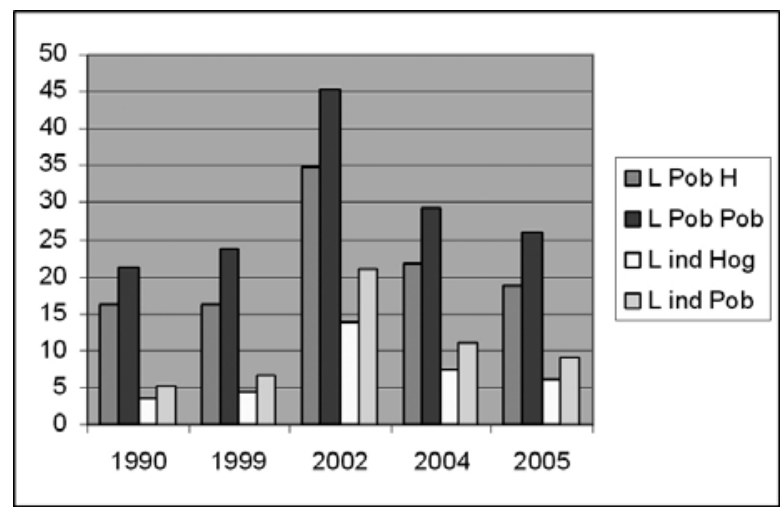

Fuente: CEPAL, Panorama Social 2006.

Después de una suave reducción de la pobreza en la primera mitad de los setenta, ésta continuó desarrollándose, en la segunda mitad, alcanzando el 7\%. La indigencia en esa época era aún poco significativa, ya que sólo afectaba al $2 \%$ de los hogares. Sin embargo, en los años 80 , la crisis económica, la fuerte inflación y el deterioro creciente de la distribución del ingreso llevaron a un rápido desarrollo de la pobreza, que llegó a afectar al $16 \%$ de los hogares y a más del $20 \%$ de la población. A principios de los noventa, como se observa en la Gráfica 10, el número de hogares indigentes se había incrementado al doble, $4 \%$ y el de los indigentes al 5\%.

Durante los años noventa la pobreza permaneció en los mismos niveles, pero sufrió un nuevo deterioro grave a principios del nuevo milenio, llegando a su nivel máximo, al afectar al 35\% de los hogares y al $45 \%$ de la población, en el 2002. En los siguientes 3 años, la pobreza disminuyó, afectando, en 2005, a menos de la quinta parte de los hogares y a un poco más de la cuarta parte de la población. Ese año la indigencia afectaba al 9\% de la población y al 6\% de los hogares.

\section{Evolución de la Pobreza en Brasil en la década de los Noventa.}

La pobreza en Brasil estaba muy extendida a mediados de los años 50 del siglo pasado y era la mayor de los cuatro países analizados, como nos los revela el bajo ingreso per cápita de Brasil y su inequitativa distribución del ingreso y aunque se redujo considerablemente entre 1950 y 1980. En la década de los 70 el número de pobres disminuyó en un 13.2\% y el de indigentes en un n10\% (Hernández L. y Velázquez R; 2003; 35). La pobreza, en 1979, afectaba al 49\% de la población en Brasil, mientras que en México, afectaba al 34\% y en Argentina, sólo al 8\% (Altimir; 1979, 63). La 
proporción de indigentes en Brasil alcanzó, ese mismo año, el 25\%, mientras que era de $12 \%$ en México, de $6 \%$ en Chile y de, tan sólo $1 \%$, en Argentina. La crisis económica de los años ochenta impactó fuertemente en Brasil, por lo que el número de pobres absolutos se incrementó en un 35\%, en esa década, y el de indigentes en un 24\% (Hernández L. y Velázquez R; 2003; 35).

A lo largo de la década de los noventa la pobreza se redujo en forma considerable en términos relativos, bajando del $41 \%$ al 30\%, como también la indigencia que se redujo del $18 \%$ al 10\% (Ver, gráfica 11). Durante los primeros años del nuevo siglo, tanto la pobreza como la indigencia se mantuvieron en los mismos niveles, reduciéndose en 1.5\%, en el 2005.

\section{Gráfica 11 Evolución de la Pobreza en Brasil: 1990-2005}

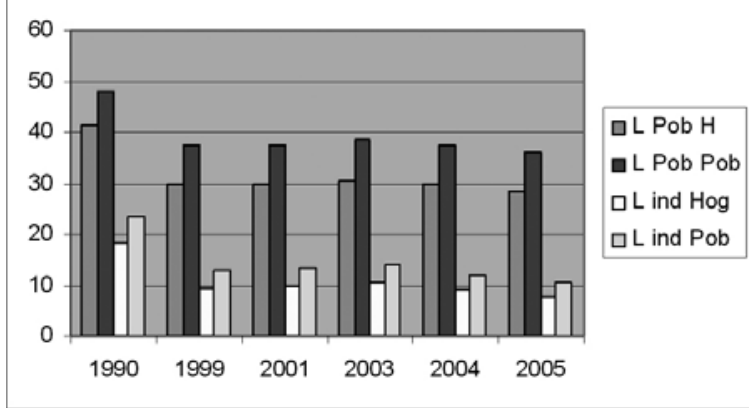

Fuente: CEPAL, Panorama Social 2006.

\section{Evolución de la Pobreza en Chile en la década de los Noventa}

Durante los años 50 se presentó una clara tendencia a la reducción de la pobreza urbana, en Chile, reduciéndose a la mitad entre 1957 y 1968; la proporción de los hogares pobres bajó del 50\% a menos del 30\% (Altimir, O; 2001; 137). La pobreza agraria, igualmente, se redujo, en esos años, como resultado de la reforma agraria de 1965 . A principios de los 70, el gasto público social y los servicios sociales se expandieron beneficiando a los pobres y a las clases medias. Sin embargo, el Golpe de Estado que llevó a cabo el General Pinochet al deponer al Presidente Allende, cortó de tajo esa tendencia, al establecer un régimen dictatorial que controló los movimientos laborales y limitó los salarios. Como consecuencia la indigencia y la pobreza se incrementaron abruptamente. En 1980, tanto la pobreza como la indigencia alcanzaron el doble de su nivel de 1968. Durante la crisis de los 80, la incidencia de la pobreza creció aún más, la profunda recesión que redujo el ingreso per cápita en un quinto generó un desempleo abierto que 
afectó a más de la cuarta parte de la población, incrementando la pobreza en un $20 \%$.

\section{Gráfica 12 \\ Evolución de la Pobreza en Chile: 1990-2005}

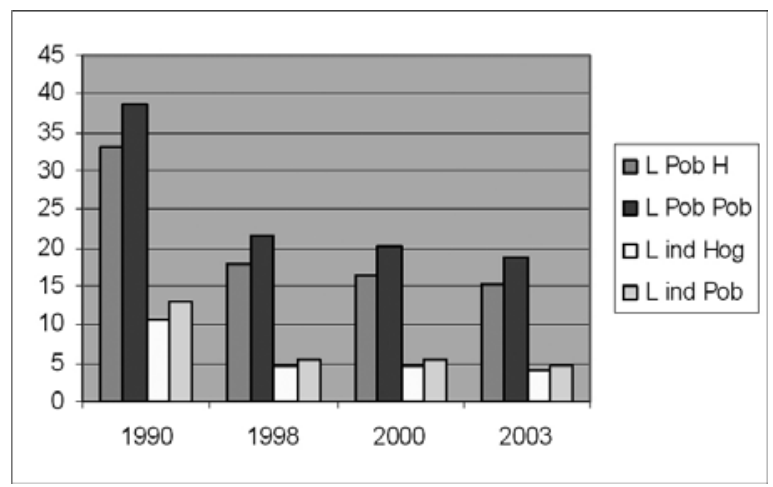

Fuente: CEPAL, Panorama Social 2006.

El nuevo régimen implantó un programa de gobierno dirigido a reducir las dimensiones del Estado y a sanear sus finanzas, por lo que se redujo el gasto social, en salud, en educación y se procedió a privatizar las empresas públicas. En 1987, la economía se recuperó, pero los niveles de pobreza tanto urbana como rural seguían siendo muy altos, de 39\%. El cambió hacia un régimen democrático, en los 90, generó una mejora en las condiciones laborales y una mayor atención a la inversión en capital humano, por parte del Gobierno, y consolidó la economía, que tuvo un crecimiento económico sostenido del producto per cápita a una tasa media anual del 5\%, permitiendo que se instaurara una tendencia a la disminución de la pobreza, nuevamente. Por lo que la pobreza se redujo de 39\%, en 1987, a 24\%, en 1994 y a 20\%, en 1998 y la indigencia se redujo del 14\% al 5\%. En ese mismo período la pobreza rural bajo a la mitad de $45 \%$ a $23 \%$.

\section{Evolución de la Pobreza en México en la década de los Noventa}

En la Gráfica 10, se presentan estimaciones sobre la evolución de la pobreza extrema (línea 1), de capacidades (línea 2) y patrimonial (línea 3) en la década de los noventa. El grado de pobreza existente en el país, en 1992, era muy elevado, ya que más de una quinta parte de los individuos y la sexta parte de los hogares se veían afectados por la pobreza extrema, $28 \%$ de los individuos y más de la quinta parte de los hogares padecían pobreza moderada y más de la mitad de los individuos y casi la mitad de los hogares padecían de pobreza patrimonial. 


\section{Gráfica 13 \\ Evolución de la Pobreza en México: 1992-2000 \\ (\%)}

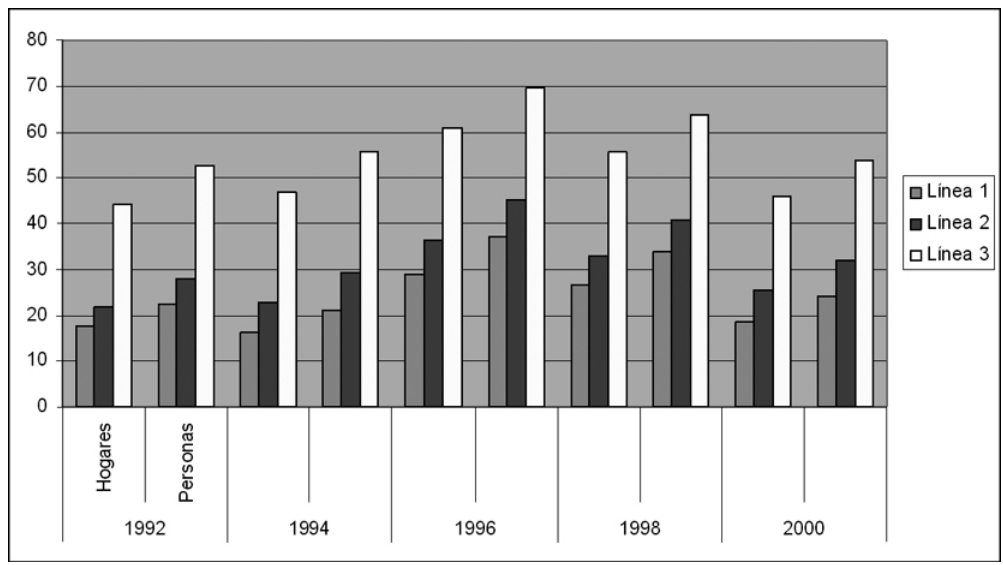

Fuente: Cortés, Hernández, Hernández Laos, Székely y Vera, 2003.

El grado de pobreza existente en el país se agravó severamente entre 1992 y 1996, ya que los tres tipos de pobreza, tanto para los individuos como para los hogares se incrementaron en un 15\%. Ello como resultado de la crisis económica de 1995, ya que entre 1992 y 1994 la pobreza se mantuvo prácticamente estancada.

Entre 1996 y el año 2000, el nivel de pobreza extrema y de capacidades, de los individuos, disminuyó en un 13\% de la población y el de pobreza patrimonial en 16\%; también, el nivel de pobreza de los hogares disminuyó, pero sin alcanzar el nivel de pobreza de 1992, que ya era muy elevado. En el año 2000, padecían de pobreza extrema cerca de 1/5 de los hogares; de pobreza de capacidades 1/4 de los hogares y de pobreza patrimonial _ de la población. De manera que, entre 1992 y el año 2000, la pobreza de los hogares se incrementó tanto en términos relativos, como también en términos absolutos, ya que el número de individuos en condición de pobreza extrema se incrementó en 4.7 millones.

\section{Conclusiones}

El PIB per cápita sigue siendo un buen indicador del desarrollo que nos indica con un alto grado de precisión los países que avanzan en su desarrollo y aquéllos otros que se retrasan o se estancan, toca a los investigadores indagar las causas de las diferencias en los ritmos de desarrollo usando otros elementos. Como vimos en la primera sección, la causa gene- 
ral del estancamiento económico es la pobreza entendida ésta, no sólo como la falta de alimentos y demás satisfactores para cubrir las necesidades básicas y lograr la supervivencia, sino como la falta de libertad y derechos para desplegar las capacidades de las personas y vivir en forma digna. De esta manera, el escaso desarrollo que tuvo México durante la colonia española se explica por las condiciones de sometimiento y explotación a que estuvo sometida la población indígena, por la falta de derechos y el escaso acceso a los servicios básicos de alimentación, salud, educación, vivienda y por la inequitativa distribución del ingreso que se hacía del producto que contribuían a elaborar. Es imposible que el PIB per cápita crezca rápidamente cuando la mayor parte de la población vive en la pobreza y es explotada a niveles tales que aún la supervivencia y la reproducción de la población no queda plenamente garantizada. Como nos ha mostrado la historia y la existencia de sociedades esclavistas y de colonias por prolongados períodos de tiempos, los pobres no poseen capacidades políticas, militares y económicas para financiar las luchas para su liberación, pero participan cuando se les orienta y se les dota de estas capacidades. En México, los pobres participaron activamente a lo largo del siglo XIX, tanto en la lucha por la independencia y soberanía política del país, como en contra de las invasiones extranjeras y en las guerras civiles, pero sin obtener un cambio radical en su condición de pobreza. A finales de siglo, durante la dictadura de Porfirio Díaz, no eran propietarios de tierras, ni de sus viviendas, ni gozaban de derechos o de una retribución equitativa, por el contrario, eran sometidos a una extrema explotación y una continua humillación como peones en las Haciendas. Así, mientras que los EUA habían incorporado los derechos humanos como parte de sus leyes y la mayor parte de la población era propietaria de sus tierras y sus habitantes podían vivir libremente en un país que les permitió desplegar sus capacidades, incorporar los adelantos e innovaciones de la revolución industrial, por el contrario, la mayor parte de las poblaciones de México, Brasil y los países latinoamericanos habitados mayoritariamente por indígenas y mestizos seguían en la pobreza, por lo que se creó una brecha económica enorme, pero también, política y social, haciendo que el bienestar material y la calidad de vida fuera muy superior en los EUA, como lo refleja la diferencia en el ingreso per cápita. La tercera sección nos muestra que en el siglo XX, a partir de los años 30, los países de América Latina pudieron crecer a la par que los EUA y otros países desarrollados, pero que no pudieron cerrar la brecha económica y social que los separaba. Nos muestra, también, que a finales de siglo, a partir de la década de los 80, la brecha se volvió a ampliar, que el aumento del PIB per cápita de Argentina, Brasil, México y Chile se estancó, nuevamente, y volvió a retrasar. Este retraso ha venido acompañado, como cabía esperar, de una degradación de las condiciones económicas y sociales de sus poblaciones y de un aumento de la pobreza, de la pérdida de capacidades de sus poblaciones para poder sustentar una vida digna. Este retraso no ha resultado temporal, sino que se ha prolongado por más de un cuarto de siglo y no se percibe un cambio drástico en las condiciones económicas, sociales y políticas hacia condiciones mejores de vida, Ello muestra un fracaso rotundo en las políticas aplicadas por los Gobiernos y de las medidas recomendadas por los organismos internacionales conocidas como el consenso de 
Washington, que prometían un cambio en el mediano y largo plazo. Es por ello, necesario un drástico viraje en el modelo económico y político de desarrollo y que se adopte un nuevo modelo cuyo objetivo primordial sean las personas y no el control de precios, la estabilidad o garantizar condiciones de rentabilidad a las inversiones extranjeras y nacionales, el objetivo primordial del modelo debe ser abatir la pobreza hasta erradicarla, dotar a la población de los servicios básicos de educación, salud, alimentos, vivienda, empleo, garantizándole una justa distribución de los ingresos y permitiéndole participar en un desarrollo económico, social, cultural y político en el cual pueda realizarse plenamente. 


\section{Bibliografía}

Altimir, Óscar (2003), “Long-term Trenes of Poverty in Latin American Coutries”. Estudios de Economía vol. 28, número 1, Universidad de Santiago de Chile, Santiago, Chile.

Banco Mundial (1992), “La medición de la pobreza”, Comercio Exterior, Vol. 42, núm 4, México.

Boltvinik, Julio (2003), “Pobreza desarrollos conceptuales y metodológicos...”, Comercio Exterior, vol 53, núm 5, México.

Boltvinik, Julio (2003), “Conceptos y medición de la pobreza. La Necesidad de Ampliar la Mirada”. Papeles de Población, número 038. Universidad Autónoma del Estado de México, Toluca, México.

Boltvinik, J. y Hdez Laos, Enrique (1999), Pobreza y distribución del ingreso en México. Siglo XXI Editores, México.

Cortés, Fernando (2002), “Consideraciones sobre la marginalidad, marginación, pobreza y desigualdad en la distribución del ingreso”. Papeles de Población, número 31. Universidad Autónoma del Estado de México, Toluca, México.

Cortés, Fernando (2006), “¿Disminuyó la pobreza? México 2000-2002”. En (Ordónez, Enríquez, Román y Valencia, 2006, p. 193-225).

Cortés, F.; Hdez, E.; Hdez Laos; Székely, M. y Vera, H. (2003), "Evolución y características de la pobreza en la última década del siglo XX”. Economía Mexicana, vol XII, núm.2, CIDE, D. F., México.

CONAPO (2001) Índices de marginación 2000, México.

Coatsworth, J. (1998), Latin America and the World Economy since 1800, Ed. Cambridge, Harvard University, David Rockefeller Center for Latin America Studies. EUA.

Hernández Laos (2000), “Crecimiento económico, distribución del ingreso y pobreza”, Comercio Exterior, vol 50, núm 10, México.

Levy, Santiago (1999), “La pobreza en México”, en Vélez Féliz, La pobreza en México. Causas y políticas para combatirla. Fondo de Cultura Económica, México.

Ordónez, Gerardo y Reyes Sergio (2006), Los retos de la política social en la frontera norte de México, El Colegio de la Frontera Norte - Plaza y Valdés Editores, México.

Ordónez, Enríquez, Román y Valencia (2006), Alternancia, políticas so- 
ciales y desarrollo regional en México. Ed. El Colegio de la Frontera Norte - Instituto tecnológico de Estudios Superiores de Occidente - Universidad de Guadalajara, México.

Ordóñez, Gerardo y Ortega, Guadal (2006), "La lucha contra la pobreza en el Gobierno de Fox: continuidad en la alternancia”. En Ordónez, Enríquez, Román y Valencia, 2006, p. 159-192.

Ornelas, Jaime (2006), "La política de combate a la pobreza en México, 1982-2005”, Papeles de Población, número 47. Universidad Autónoma del Estado de México, Toluca, México.

Loyola, Juan (2006), “Desigualdad y pobreza en los estados fronterizos del norte de México”, en Ordónez y Reyes, 2006, p. 99 -119).

Rojas, Georgina (2003), "El peso de los recursos: determinantes de la pobreza en hogares de Monclava, Aguascalientes y la Ciudad de México”, Papeles de Población, número 038. Universidad Autónoma del Estado de México, Toluca, México.

Rojas, Mariano (2006), "Well-being and the Complexity of Poverty: A Subjective Well-being Approach”, en Mc Gillivary: Perspectives of Human Well-being, United, Nations, University Press.

Scott, John (2004), "La descentralización, el gasto social y la pobreza en MéxicoÑ. Gestión y Política Pública, vol. XIII, número 3, CIDE, D.F., México.

Sen, Amrtya (1997), Sobre ética y economía. Ed. Alianza, México.

Székely, Miguel (1998), The economics of poverty, inequality and wealth accumulation in Mexico. MacMillan, London.

Székely, Miguel y Rascón, Ericka (2005), “Reducción de la Pobreza con Estabilidad y Expansión de Programas Sociales”, Economía Mexicana, vol. XIV, número 002, CIDE, México.

The World Bank (2004), Poverty in Mexico: an assessment of conditions, trends, and Government strategy. The World Bank, México.

WIDER (1996), The quality of life. United University of Nations-Fondo de Cultura Económica, México. 